\title{
Review of Surveying Devices for Structural Health Monitoring of Cultural Heritage Buildings
}

\author{
Jakub Markiewicz \\ Faculty of Geodesy and Cartography \\ Warsaw University of Technology \\ Warsaw, Poland \\ jakub.markiewicz@pw.edu.pl \\ Magomed Muradov \\ BEST Research Institute \\ Liverpool John Moores University \\ Liverpool, United Kingdom \\ m.muradov@ljmu.ac.uk
}

\author{
Aleksandra Tobiasz \\ Documentation and Digitalization Department \\ Museum of King Jan III's Palace at Wilanow \\ Wilanów, Poland \\ atobiasz@muzeum-wilanow.pl
}

\author{
Andy Shaw \\ BEST Research Institute \\ Liverpool John Moores University \\ Liverpool, United Kingdom \\ a.shaw@1jmu.ac.uk
}

\author{
Patryk Kot* \\ BEST Research Institute \\ Liverpool John Moores University \\ Liverpool, United Kingdom \\ p.kot@ljmu.ac.uk \\ Ahmed Al-Shamma'a \\ BEST Research Institute \\ Liverpool John Moores University \\ Liverpool, United Kingdom \\ a.al-shamma'a@ljmu.ac.uk
}

\begin{abstract}
Cultural heritage is the evidence of the past. Nowadays monumental objects create the important part of the cultural heritage, so it is essential to document this type of objects and perform structural health monitoring analysis for preservation. Currently, the digital architectural documentation is recorded as vector drawings, digital object models, 3D models or orthoimages, which are the obligatory form of the inventory of historical objects [1]. In order to generate this type of high resolution and high quality documentation, different sensors as well as appropriate methods are used. The aim of this paper is to present both the conception of the novel surveying device (based on RGB camera, Terrestrial Laser Scanning - TLS with electromagnetic sensor) and methodology of data processing. This paper will review existing state of the art sensors and discuss their advantages and disadvantages as well as the further improvement of such sensors. Additionally, the conception of the new architectural documentation will be described.
\end{abstract}

Keywords- Cultural Heritage, Electromagnetic Sensor, Surveying Device, Structural Health Monitoring,

\section{INTRODUCTION}

In order to perform architectural documentation and visualization of cultural heritage objects, close-range photogrammetric methods based on different sensors such as RGB cameras, Terrestrial Laser Scanners or multispectral cameras, have been widely used. The generation of the highresolution documentation based on the image-based and range-based techniques is still an open issue, which forms many challenges [2]-[4]. Although, well-known data processing algorithms, such as Structure-from-Motion, MultiViewStereo, multi-source data co-registration are intensively developed with consideration of e.g. 3D models generation, high-resolution orthoimage processing or generation of accurate vector drawings, the limitations concerning the utilisation of measuring sensors are still the issue, which should be solved [2].

The main research strand aiming to optimize integration and analysis of historical objects, focuses on the integration of data acquired by several measuring technologies [1], [5]-[7]. Combining data from terrestrial laser scanning and image matching is increasingly used to improve the quality of products [8]. Integration of measuring technologies can result in the elimination of the weaknesses of one by the advantages of the other, i.e:

- based on the classical photogrammetric and TLS approach it is possible to obtain high quality and resolution 3D models or orthoimages,
- $\quad$ based on the TLS intensity or multispectral sensors it is possible to analyse not only the shape, but also the condition of the tested object, but unfortunately only in the short depths of the object

- $\quad$ adding the electromagnetic sensor will provide a depth measurement and information about the condition of the tested object.

The aim of this paper is to present the novel surveying device based on the RGB camera, TLS sensor and electromagnetic sensor to provide more detailed analysis of the object under test.

\section{THE STATE-OF-THE-ART}

\section{A. Image-based and range-based techniques used for $3 D$ shape reconstruction}

The current photogrammetric measuring technologies allow for complete photogrammetric documentation using passive (image-based) and active (range-based) measuring methods to develop 3D shape and architectural documentation such as orthoimages, cross-sections, vector drawing or digital surface objects models [3], [9]-[11]. The figure 1 presents the general diagram for the division of methods applied for $3 \mathrm{D}$ modelling and shape reconstruction.

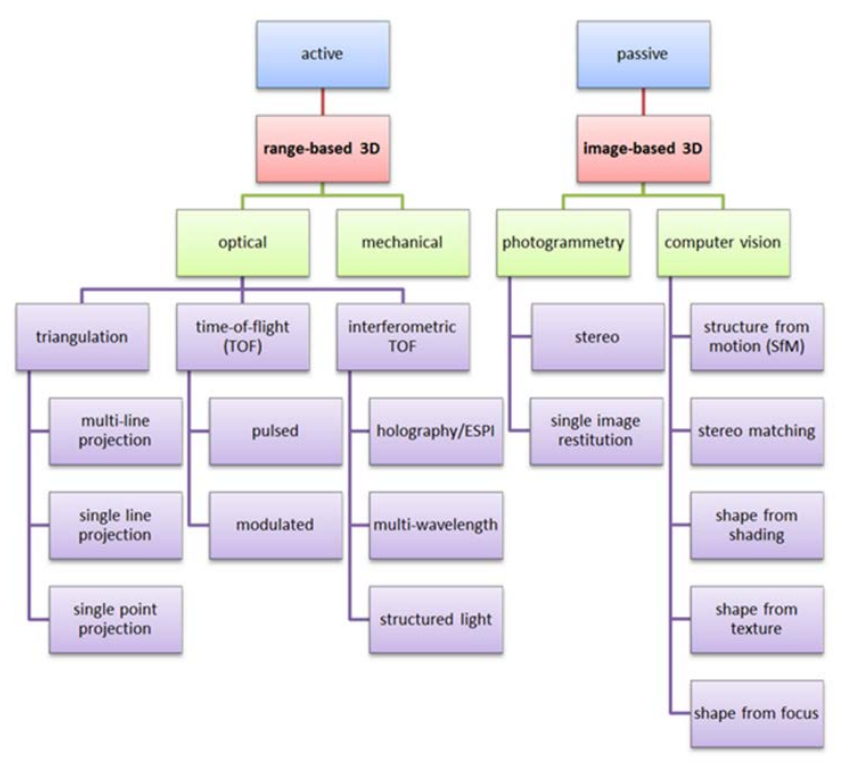

Figure 1. Division of 3D modelling methods [12]. 
Selection of an appropriate method for 3D shape reconstruction depends on many factors, such as the objectivise of the inventory, the object's volume, sumptuousness of architectural design, accessibility to the object, required terms and accuracy of work [1]. For completing documentation of old buildings, historic walls or other similar objects, image-based (Structure-frommotion/Photogrammetry) as well as range-based (i.e. Terrestrial Laser Scanning) techniques are commonly used [3], [9]-[11].

Nowadays, terrestrial laser scanning (TLS) becomes one of the most important techniques for the $3 \mathrm{D}$ investigation of historical objects and monuments. The unquestionable assets of this technology are its high accuracy, possibility of measuring billions of 3D points and high level of automation of measurements [13]. Based on the angular-and-linear measurements, the scanner also records the laser-beam reflectance intensity, which might be used to investigate properties of the analysed object [14]. Laser scanning systems can obtain data that can vary in terms of point density, fieldof-view (FOV), the amount of noise, incident angle, waveform and texture information [15], but the main advantage is the possibility to measure untextured areas. Despite its high popularity, the terrestrial laser scanning method also has some drawbacks, which are mainly connected with instrumental errors and their influence on the acquisition accuracy. The laser beam propagates with distance, which can result in uncertainty regarding the location of the determined point [16]. Another source of errors in TLS measurements is reflectivity of the investigated objects. The laser beam is fully absorbed by elements of too-low reflectivity; this results in data gaps within the point cloud. In the case of highreflectivity surfaces, the reflected laser beam does not reach the detector and therefore the locations of points are incorrectly determined [1]. Mixed edge problem is one of the most important consequences of the beam divergence and it occurs when the laser beam hits an edge of an object. It is divided into the two parts: one part reflects and the other one travels further and hits another surface. This unwanted behaviour generates noise, because the coordinates of this point are calculated as an average of several returned signals. And the last group, but not least are the problems bonded with the temperature and atmosphere conditions.

Modern image-based close-range photogrammetry depends on the Structure-from-Motion (SfM) and Multi-View Stereo (MVS) approach, which allows for digital reconstruction of the object with the required accuracy and high level of detail [4], [17]-[19]. The SfM/MVS approach is a combination of photogrammetric and computer vision methods. It is a fully automated $3 \mathrm{D}$ reconstruction technique, which refers to simultaneous estimation of camera orientation, self-calibration and dense point cloud generation [4]. The idea of photogrammetric image-based approach is to establish correspondence between primitives extracted from minimum two, but usually more images. Those corresponding primitives are converted into the $3 \mathrm{D}$ point cloud using the mathematical model [20]. The main aspect connected with the image-based method is the possibility of the image correlation, which is the most important issue during the $3 \mathrm{D}$ reconstruction that affects the quality and accuracy of this reconstruction. This matter has been studied for more than 30 years, but still many problems exist such as: no possibility of automatic completion, occlusions, blank or poorly-textured areas, repetitive structures etc. [21]. The main disadvantage of the image matching method regarding objects of uniform texture is the impossibility to find homologous points in order to reconstruct the $3 \mathrm{D}$ shape.

\section{B. Multispectral and hyperspectral remote sensing}

Exact shape reconstruction of cultural heritage objects is the source of information about physical phenomena posing threat to historical treasures. On the other hand, spectral measurements reveal the object features, which usually cannot be seen with the naked eye. Unlike the traditional, invasive methods of artifacts examination commonly used by conservators, which involve taking samples from selected parts of the object, methods employing spectral analyses are contactless and therefore allow to minimise the risk of possible damage or destruction of the artifacts. Analyses based on multispectral and hyperspectral imagery captured by both passive and active sensors are applied in works regarding historical artifacts of many kind including huge monuments and buildings [22]-[24], sculptures [25], [26], paintings and wall paintings [27]-[31] and parchment [32].

Spectral data are commonly associated with 2D products such as orthoimages while studying 2D objects like paintings or walls whereas $3 \mathrm{D}$ modelling relates to $3 \mathrm{D}$ objects [33]. However, this approach limits the scope of information possible to obtain. To get a comprehensive view of an object it is recommended to integrate spectral information with the object's geometry. Finding optimal way to integrate multispectral data with geometric information was a subject of several studies [14], [33], but nevertheless this issue is still remaining.

The idea of multispectral and hyperspectral imaging is to acquire images of a certain object or scene in a few up to several hundred ranges of electromagnetic radiation wavelengths called spectral bands. The result of hyperspectral imaging is an image cube consisting of hundreds of spatially registered images of the scene taken over a large wavelength region, where each pixel represents the reflected energy spectrum of the materials within the spatial area covered by the pixel [34].

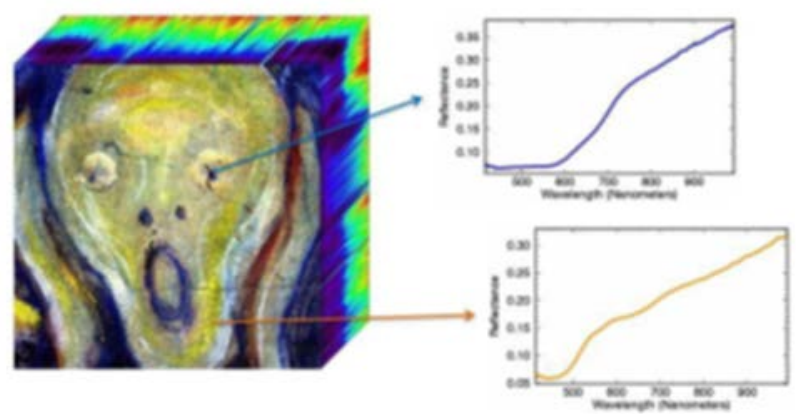

Figure 2. Edvard Munch, The Scream - Hyperspectral image cube, showing that for every pixel a characteristic spectrum related to material content is obtained [27].

Spectral imaging is best known for its use in aerial and satellite remote sensing. Multispectral imaging systems (e.g. Landsat) have been used for land cover monitoring and classification since the 1970 s and even today they play a significant role in this field. Hyperspectral systems such as aerial AVIRIS or satellite HYPERION provide data of high spectral resolution, which was the reason for development of many image processing algorithms. 
The use of multi- and hyperspectral imaging in cultural heritage started in 1990s [35]. Earlier around the 1980s spectrophotometry was used as a non-invasive method in conservation and restoration of paintings. Spectrophotometry allowed for measuring spectral reflectance relating to chemical composition and physical features of captured object, but its potential was limited due to spot reading [27].

\section{Methodology}

The distinction between multispectral and hyperspectral imaging is not clearly defined, but the general workflow for each of them differs. Hyperspectral imagery contains a larger number of narrower spectral bands than multispectral imagery, providing higher spectral resolution [30], [36]. Hyperspectral sensors collect several hundred images corresponding to wavebands, which are adjacent to each other whilst multispectral ones measure electromagnetic spectra, which are not necessarily contiguous [27], [36]. Moreover, in multispectral devices usually bandpass filters are used in contrast to hyperspectral sensors exploiting more advanced solutions such as acousto-optical tuneable filters (AOTFs), liquid-crystal tuneable filters (LCTFs) [36] or grating spectrometers [37].

Studies of cultural heritage objects based of spectral imagery exploit variety of methodologies depending on the object (it's size, shape, material, location and accessibility) as well as the purpose of the experiment. That's why it is not possible to specify one workflow. However, there are several issues, which have to be considered in every case.

Selection of wavebands to be captured as well as selection method are crucial matters. Wavelengths can be selected either "through illumination" so that only a selected wavelength range is incident on an object at a time, or "in the reflected light", so that the light reflected from the object are separated spectrally [36].

Different parts of spectrum are used for different purposes, for instance, for pigment identification usually VIS and IR spectral bands are used while SWIR allow for recognition of materials under the paint (e.g. cardboard) [27]. Infrared spectral bands are also useful for detection of damages, which have been repaired [36]. Several studies suggested the possibility to detect and map moisture and other damage using near infrared radiation emitted by a terrestrial laser scanner [38], however it is recommended to correct intensity data due to range and incidence angle effects affecting raw intensity values [39]. Moisture can also be monitored by using SWIR imaging sensors - wavelengths around $1,4 \mu \mathrm{m}$ and $1,9 \mu \mathrm{m}$ are water absorption bands [36].

Ultraviolet (both reflectance and fluorescence - UVR and UVF respectively) can be used to enhance reading of faded paints and inks as well as to differentiate white pigments as well as to detect retouches [40].

To provide high accuracy of spectral data the imaging system needs to be calibrated. Necessary corrections include correction of accumulated thermal black current, correction of spatial inhomogeneity of illumination and correction of spectral response of the imaging system [36]. Low-cost multispectral sensors also may be affected by a vignetting effect [24], which also needs to be eliminated.

Once all radiometric and geometric corrections are made, the next step is image processing. If the object is large and was covered by many images, the images need to be joint together resulting in orthoimage generation [24]. The panoramic photographic method also can be used for this purpose [41].

Spectral imagery is classified using different classification algorithms (both supervised and unsupervised) in order to identify the material represented by a certain pixel. It is common to use both classification strategies interchangeably [42]. For multispectral imagery containing only several spectral bands it is possible to generate band compositions from selected band sets [32]. For hyperspectral imagery pixel classification can be performed, using classifiers such as Spectral Angle Mapper (SAM), Spectral Correlation Mapper (SCM) or Support Vector Machines (SVM). Another approach is spectral unmixing allowing to estimate the percentage of each material (i.e. certain pigment) in each mixed pixel.

This research will investigate the potential use of electromagnetic (EM) sensor to provide a depth and condition of the object under measurement. The EM sensors have already been used in civil engineering for monitoring excess of moisture content in building fabrics, detection of foreign objects and defects of concrete structures [43]-[45]. The measurement of required parameter is conducted by the interaction of measured object and electromagnetic wave. This interaction can be revealed in the form of a signal spectrum called reflection coefficient $\left(\mathrm{S}_{11}\right)$ and transmission coefficient $\left(\mathrm{S}_{21}\right)$. The advantage of using microwave spectroscopy is the ability to monitor the interaction of EM waves with and tested object in real time. As a result it is possible to observe changes of microwave spectrum due to the different dielectric properties and texture of measured objects. This sensor has a capability to penetrate through measured material, which provides more detailed information about the material characterisation.

\section{CONCLUSION AND FUTURE WORK}

This paper has reviewed a current surveying devices for structural health monitoring of cultural heritage buildings. The advantages and drawbacks of each technique were discussed. The future work will involve development of a novel surveying device for structural health monitoring of cultural heritage buildings by combining three selected techniques (RGB camera, Terrestrial Laser Scanning - TLS with electromagnetic sensor). The experimental work will be performed at the Museum of King Jan III's Palace at Wilanów, Poland.

\section{ACKNOWLEDGMENT}

The authors gratefully acknowledge Museum of King Jan III's Palace at Wilanów for providing the access to museum facilitates for experimental testing of the novel sensor. Authors received a funding from the European Union's Horizon 2020 research and innovation programme under the grant agreement DigiArt 665066. 


\section{REFERENCES}

[1] J. S. Markiewicz, D. Zawieska, R. Sensing, and S. I. Systems, "Terrestrial scanning or digital images in inventory of monumental objects? - Case study," in The International Archives of the Photogrammetry, Remote Sensing and Spatial Information Sciences,ISPRS Technical Commission V Symposium, 2014, vol. XL, no. June, pp. 23-25.

[2] W. Boehler and A. Marbs, "3D scanning and photogrammetry for heritage recording: a comparison," in Proc. 12th Int. Conf. on Geoinformatics - Geospatial Information Research: Bridging the Pacific and Atlantic, 2004, no. June, pp. 7-9.

[3] F. Remondino and S. El-Hakim, "Image-based 3d modelling: a review," Photogramm. Rec., vol. 21, no. September, pp. 269-291, 2006.

[4] W. Moussa, "Integration of Digital Photogrammetry and Terrestrial Laser Scanning," 2014.

[5] A. Guarnieri, F. Remondino, and A. Vettore, "Digital photogrammetry and TLS data fusion applied to cultural heritage $3 \mathrm{~d}$ modelling," 2005.

[6] M. M. Ramos and F. Remondino, "Data fusion in cultural heritage - a review," in The International Archives of the Photogrammetry, Remote Sensing and Spatial Information Sciences, 25th International CIPA Symposium, 2015, no. September, pp. 359363.

[7] J. S. Markiewicz, P. Podlasiak, and D. Zawieska, “A New Approach to the Generation of Orthoimages of Cultural Heritage Objects - Integrating TLS and Image Data," Remote Sens., vol. 7, pp. 16963-16985, 2015.

[8] M. L. V. Baptista, "Documenting a complex modern heritage building using multi image close range photogrammetry and $3 \mathrm{~d}$ laser scanned point clouds," Int. Arch. Photogramm. Remote Sens. Spat. Inf. Sci. XXIV Int. CIPA Symp., no. September, pp. 675-678, 2013.

[9] R. Arif and K. Essa, "Evolving techniques of documentation of a world heritage site in Lahore," in The International Archives of the Photogrammetry, Remote Sensing and Spatial Information Sciences, 26th International CIPA Symposium, 2017, no. September, pp. 33-40.

[10] S. G. Barsanti, F. Remondino, and D. Visintini, “3D surveying and modelling of archaeological sites some critical issues," in ISPRS Annals of the Photogrammetry, Remote Sensing and Spatial Information Sciences. XXIV International CIPA Symposium, 2013, vol. II, no. September, pp. 2-6.

[11] P. Grussenmeyer and J. Yasmine, "Photogrammetry for the preparation of archaeological excavation . A $3 \mathrm{D}$ restitution according to modern and archive images of Beaufort Castle landscape (Lebanon) Photogrammetry for the preparation of archaeological excavation. A 3D Restitution" in XXth Congress of the International Society for Photogrammetry and Remote Sensing (ISPRS), 2004, no. June, pp. 1-7.

[12] G. Verhoeven, "Tutorial Using SfM-based
Applications in Archaeology." Riva del Garda, ISPRS Technical Commission V Symposium, 2014.

[13] P. Bastonero, E. Donadio, F. Chiabrando, C. Heritage, and T. Preservation, "Fusion of 3D models derived from TLS and image-based techniques for $\mathrm{CH}$ enhanced documentation," in ISPRS Annals of the Photogrammetry, Remote Sensing and Spatial Information Sciences. ISPRS Technical Commission V Symposium, 2014, vol. II, no. June, pp. 23-25.

[14] S. J. Buckley, T. H. Kurz, D. Schneider, and R. Sensing, "The benefits of terrestrial laser scanning and hyperspectral data fusion products," in International Archives of the Photogrammetry, Remote Sensing and Spatial Information Sciences, XXII ISPRS Congress, 2012, no. September, pp. 541546.

[15] P. Grussenmeyer, E. Alby, T. Landes, M. Koehl, S. Guillemin, J. Hullo, P. Assali, and E. Smigiel, "Recording approach of heritage sites based on merging point clouds from high resolution photogrammetry and terrestrial laser scanning," in International Archives of the Photogrammetry, Remote Sensing and Spatial Information Sciences. XXII ISPRS Congress, 2012, no. September, pp. 553558.

[16] B. Van Genechten, Theory and practice on Terrestrial Laser Scanning Training material based on practical applications. 2008.

[17] S. Bianco, "Evaluating the Performance of Structure from Motion Pipelines," J. Imaging Artic., vol. 4, pp. 1-18, 2018.

[18] F. Chiabrando, E. Donadio, and F. Rinaudo, "SfM for orthophoto generation: a winning approach for cultural heritage knowledge," in The International Archives of the Photogrammetry, Remote Sensing and Spatial Information Sciences, 25th International CIPA Symposium, 2015, no. September, pp. 91-98.

[19] M. J. Westoby, J. Brasington, N. F. Glasser, M. J. Hambrey, and J. M. Reynolds, "Geomorphology " Structure-from-Motion ' photogrammetry: A lowcost , effective tool for geoscience applications," Geomorphology, vol. 179, pp. 300-314, 2012.

[20] F. Chiabrando and A. Spanò, "Points clouds generation using TLS and dense-matching techniques. A test on approachable accuracies of different tools.," ISPRS Ann. Photogramm. Remote Sens. Spat. Inf. Sci. XXIV Int. CIPA Symp., no. September, pp. 2-6, 2013.

[21] F. Remondino and F. Menna, "Image-based surface measurement for close-range heritage documentation," in The International Archives of the Photogrammetry, Remote Sensing and Spatial Information Sciences, 2008, pp. 199-206.

[22] M. Hemmleb, F. Weritz, A. Schiemenz, A. Grote, C. Maierhofer, and L. Scanning, "Multi-spectral data acquisition and processing techniques," 2005, pp. 16.

[23] L. Lerma, T. Akasheh, N. Haddad, and M. Cabrelles, "Multispectral Sensors in Combination with Recordnig Tools for Cultural Heritage Documentation," in Multispectral Sensors, 2010, pp. 236-250. 
[24] S. Del Pozo, J. Herrero-Pascual, B. Felipe-García, D. Hernández-López, P. Rodríguez-Gonzálvez, and D. González-Aguilera, "Multispectral Radiometric Analysis of Façades to Detect Pathologies from Active and Passive Remote Sensing," Remote Sens., vol. 8, pp. 1-16, 2016.

[25] E. Catelli, L. L. Randeberg, H. Strandberg, B. K. Alsberg, A. Maris, and L. Vikki, "Can hyperspectral imaging be used to map corrosion products on outdoor bronze sculptures?," J. Spectr. Imaging, vol. 1, pp. 1-9, 2018.

[26] S. B. Hedeaard, C. Brøns, I. Drug, P. Saulins, A. Jakovlev, and L. Kjær, "Multispectral Photogrammetry: 3D models highlighting traces of paint on ancient sculptures."

[27] H. Deborah, "Pigment Mapping of Cultural Heritage Paintings Based on Hyperspectral Imaging Master Erasmus Mundus in Color in Informatics and Media Technology ( CIMET ) Pigment Mapping of Cultural Heritage Paintings Based on Hyperspectral Imaging Master Thesis Report P,” 2018.

[28] F. Rosi, C. Miliani, R. Braun, R. Harig, D. Sali, B. G. Brunetti, and A. Sgamellotti, "Noninvasive Analysis of Paintings by Mid-infrared Hyperspectral Imaging," Angew. Chemie, vol. 52, pp. 1-5, 2013.

[29] A. Cosentino, "Identification of pigments by multispectral imaging; a flowchart method," Herit. Sci., vol. 2, pp. 1-12, 2014.

[30] L. W. Macdonald, T. Vitorino, M. Picollo, R. Pillay, M. Obarzanowski, J. Sobczyk, S. Nascimento, and J. Linhares, "Assessment of multispectral and hyperspectral imaging systems for digitisation of a Russian icon," Herit. Sci., vol. 5, pp. 1-16, 2017.

[31] G. Bonifazi, G. Capobianco, C. Pelosi, and S. Serranti, "Hyperspectral Imaging as Powerful Technique for Investigating the Stability of Painting Samples," J. Imaging, vol. 5, pp. 1-19, 2019.

[32] L. Macdonald, A. Giacometti, and A. Campagnolo, "Multispectral Imaging of Degraded Parchment," in Computational Color Imaging, no. December 2016, 2013, pp. 143-157.

[33] C. S. Chane, A. Mansouri, M. Franck, B. Frank, "Integration of 3D and multispectral data for cultural heritage applications: Survey and perspectives To cite this version: HAL Id: hal-00783985," Surv. Perspect. Image Vis. Comput., vol. 31, pp. 91-102, 2013.

[34] J. C. Harsanyi, C. Chang, "Hyperspectral Image Classification and Dimensionality Reduction: An Orthogonal Subspace Projection Approach," IEEE Trans. Geosci. Remote Sens., vol. 32, no. 4, pp. 779785, 1994.

[35] C. Fischer and I. Kakoulli, "Multispectral and hyperspectral imaging technologies in conservation : current research and potential applications."
[36] H. Liang, "Advances in Multispectral and Hyperspectral Imaging for Archaeology and Art Conservation," Appl Phys A, vol. 106, pp. 309-323, 2012.

[37] J. K. Delaney, J. G. Zeibel, M. Thoury, R. O. Y. Littleton, M. Palmer, K. M. Morales, E. Rene, and A. N. N. Hoenigswald, "Visible and Infrared Imaging Spectroscopy of Picasso's Harlequin Musician: Mapping and Identification of Artist Materials in Situ," vol. 64, no. 6, pp. 584-594, 2010.

[38] P. M. Lerones, D. O. Vélez, F. G. Rojo, J. GomezGarcia-Bermejo, and E. Z. Casanova, "Moisture detection in heritage buildings by $3 \mathrm{D}$ laser scanning Moisture detection in heritage buildings by 3D laser scanning," Stud. Conserv., vol. 61, pp. 46-54, 2016.

[39] Q. Li and X. Cheng, "Damage Detection For Historical Architectures Based on TLS Intensity Data," in The International Archives of the Photogrammetry, Remote Sensing and Spatial Information Sciences, ISPRS TC III Mid-term Symposium "Developments, Technologies and Applications in Remote Sensing, ”2018, pp. 7-10.

[40] Cultural Heritage Science, "Ultraviolet Reflected Photography (UVR)," 2019. [Online]. Available: https://chsopensource.org/ultraviolet-reflectedphotography-uvr/.

[41] A. Cosentino, "Panoramic, Macro and Micro Multispectral Imaging: An Affordable System for Mapping Pigments on Artworks," J. Conserv. Museum Stud., vol. 6, pp. 1-17, 2015.

[42] S. Del Pozo, L. Engineering, C. Heritage, and L. Scanning, "Multispectral imaging in cultural heritage conservation," in The International Archives of the Photogrammetry, Remote Sensing and Spatial Information Sciences, 26th International CIPA Symposium 2017, 2017, vol. XLII, no. September, pp. $155-162$.

[43] P. Kot, A. Shaw, M. Riley, A. S. Ali, and A. Cotgrave, "The Feasibility of Using Electromagnetic Waves in Determining Membrane Failure Through Concrete," Int. J. Civ. Eng., vol. 15, no. 2, 2017.

[44] P. Kot, A. S. Ali, A. Shaw, M. Riley, and A. Alias, "The application of electromagnetic waves in monitoring water infiltration on concrete flat roof: The case of Malaysia," Constr. Build. Mater., vol. 122, pp. 435-445, 2016

[45] K. H. Teng, P. Kot, M. Muradov, A. Shaw, K. Hashim, M. Gkantou, and A. Al-Shamma'a, "Embedded Smart Antenna for Non-Destructive Testing and Evaluation ( NDT \& E ) of Moisture Content and Deterioration in Concrete," Sensors, vol. 19, no. 547, pp. 1-12, 2019. 